Research Article

\title{
Optimization of Arabian-Shield-Based Natural Pozzolan and Silica Fume for High-Performance Concrete Using Statistical Design of Experiments
}

\author{
Yassir M. Abbas $\mathbb{D D}^{1}$ and M. Iqbal Khan $\mathbb{D}^{2}$ \\ ${ }^{1}$ Department of Civil Engineering, College of Engineering, King Saud University, Riyadh, P.O. Box 800, \\ Riyadh 11421, Saudi Arabia \\ ${ }^{2}$ Department of Civil Engineering \& Managing Director, Center of Excellence for Concrete Research and Testing, \\ College of Engineering, King Saud University, Riyadh, P.O. Box 800, Riyadh 11421, Saudi Arabia \\ Correspondence should be addressed to Yassir M. Abbas; yabbas@ksu.edu.sa
}

Received 12 January 2021; Revised 21 March 2021; Accepted 25 March 2021; Published 8 April 2021

Academic Editor: Zhen-Zhong Hu

Copyright (c) 2021 Yassir M. Abbas and M. Iqbal Khan. This is an open access article distributed under the Creative Commons Attribution License, which permits unrestricted use, distribution, and reproduction in any medium, provided the original work is properly cited.

\begin{abstract}
In this study, the optimum dosages of silica fume (SF) and natural pozzolan (NP) were experimentally and statistically assessed for the best strength and durability properties of high-performance concrete (HPC). SF and NP were used as partial replacement Portland cement (PC) by up to 12 and 25 wt.\%, respectively. Additionally, the prediction models based on second-level factorial (SLF) and response surface design (RSD) were formulated to estimate the HPC properties and their validation. The SLF-based model was further employed to investigate the significance and interactions of the PC, SF, and NP blends. The 28-day strength of the blended-cement HPC with a water-to-binder ratio $(w / b)$ of 0.25 was generally higher than that of the control concrete. The positive synergy of PC-NP-SF was also observed in the HPC permeability. The paired $t$-test of the mean square error (MSE) of the SLF- and RSD-based models revealed that the MSE of the former was notably less than that of the latter. These results established the superiority of the SLF-based model over the RSD-based model. Therefore, the SLF-based model was further employed to investigate the importance of various binders.
\end{abstract}

\section{Introduction}

Portland cement $(\mathrm{PC})$ is a raw construction material that is currently consumed in huge quantities (approximately 4.0 billion tons annually), and by 2030 , its global production is projected to be approximately 5.5 billion tons $[1,2]$. The expeditious infrastructure growth in Asia, Middle East, and other developing regions in the world is expected to increase the demand for cement and concrete products [3]. The ecological footprint (e.g., greenhouse gases, $\mathrm{CO}_{2}$, and other emissions) and energy consumption involved in the production of cementitious composites have posed serious environmental hazards [4-6]. The use of recycled materials and natural pozzolan $(\mathrm{NP})$ as supplementary cementitious materials (SCMs) provides viable prospective solutions to $\mathrm{CO}_{2}$ emissions. Thus, efficient, cost-effective, and eco-friendly production of concrete using SCMs has attracted a significant research focus. Effective utilization of SCM mixtures for concrete production enhances the workability, mechanical behavior, and capacity of concrete to endure harsh environments [7-9].

Silica fume (SF), fly ash (FA), metakaolin (MK), and a broad series of NPs are regularly used as SCMs in concrete production. With regard to pozzolanic reactivity, the finer the SCM particles $(\leq 75 \mu \mathrm{m})$ are, the more favorable the cement response is $[2,3]$. Therefore, SF is probably the preferred SCM owing to its superfine particles and, consequently, its significant pozzolanic activity. However, an increase in its 
surficial area reduces the concrete workability. Therefore, the use of a superplasticizer (SP) in SF-based concrete is crucial. However, it increases the production cost of concrete. The construction industry has recently shown a profound interest in the use of NPs owing to their abundance and affordability [10]. The use of a low water-to-binder ratio $(w / b)$ to produce high-performance concrete (HPC) usually results in workability issues. However, the employment of very fine pozzolanic materials (e.g., FA and NP) can economically solve this problem [7]. The synergistic interactions of PC, FA, and SF in ternary cementitious composites were investigated in the early stages of material development (after seven days) [11]. Moreover, the use of these pozzolans could significantly enhance the strength and durability of $\operatorname{HPC}[8,9]$. In cement chemical terms, portlandite (which results from cement hydration) reacts with silicic acid (in the pozzolanic material) to produce calcium-silicate-hydrate, forming a strong matrix. Additionally, the inclusion of extremely fine materials in concrete enhances the concrete packing density (i.e., microstructural properties) and thus boosts its durability by promoting its resistance to aggressive chemical ingress.

Pieces of evidence from past research have proven the feasibility of using NP as a cost-effective and environmentally balanced SCM [12]. This natural material offers the potential for improving the workability, sustainability, and performance of concrete. The inclusion of NP in concrete is generally agreed to significantly reduce the need for chemical admixtures to control the concrete workability [13-15]. However, its influence on the strength and durability of concrete is the focus of ongoing research. The significant debate over the pozzolanicity of NP compared with that of SF and FA has been ongoing. However, the consensus is that NP is superior to FA but inferior to SF, and its ideal cement replacement level is likely to be $10 \%-20 \%$ [16-18]. Moreover, the use of NP is generally agreed to enhance the durability of cement-based materials [19-22]. Nevertheless, information on the influence of NP in HPC (with $(w / b)$ of less than 0.3$)$ is scarce. We also note that little information about the Arabian-shield-based NP exists in the literature. However, this NP variant appears to conform to the ASTM C618 criterion (likely "Class-N" category) [23]. The physicochemical and mechanical properties of scoria volcanic rock (as an NP source), which is available in various areas in the Arabian shield, were presented in [24].

The properties of cement-based materials significantly rely on the sophisticated interactions of the cementitious constituents. These reciprocal actions are complicated because several responses are synchronously desired under many conditions [25]. Therefore, the realization of an ideal material performance requires a demanding optimization process. Under these conditions, implementation of the design of experiments (DOE) may be necessary. DOE is an efficient statistical method for evaluating the hydration and strength properties of cementitious systems that contain blast-furnace slag, which is activated by sodium carbonate $\left(\mathrm{Na}_{2} \mathrm{CO}_{3}\right)$ [26]. The advantages of the simplex-DOE method were compared with those of the conventional methods in terms of strength and heat conductivity multiparameter optimization of a lime-pozzolan-based composite, FA, and slag $[27,28]$. The response surface design (RSD) of this technique was also effectively employed to predict and optimize the behavior of a geopolymer composite that contained recycled muck, rice-husk ash, Earth diatomite, MK, and limestone (LS) $[28,29]$. Furthermore, the Taguchi DOE approach was successfully used to optimize a green-concrete mixture that incorporated recycled aggregate and FA [30]. We need to note that DOE was also used to develop cementitious composites that incorporated various components of micro- and nanosilica and polymeric fibers [31]. One of the difficult challenges for researchers in this domain is that the conventional (empirical) optimization processes are still employed by material-design practitioners, possibly because of the high cost of analysis and expertise required in modern optimization techniques compared with that of the empirical methods that deliver expeditious results.

Optimized concrete-mix proportioning is a process of determining the type and amount of its ingredients. The objective of this design (qualitative or performance-based) process is to develop concrete with specific standard workability, strength, and durability properties [32]. Moreover, statistical DOE is usually employed to develop the interactions between the important design variables and targeted concrete performance by considering the applicable constraints while minimizing the experimental cost [33]. Furthermore, DOE is conventionally used to define the biased effect of the individual component of concrete using an objective performance target and their second-order isoresponse interactions [34]. We must note that this statistical approach uses continuous analytical formulas for the observed response surface, which can lead to multitarget optimization.

The sustainability, environmental issues, and performance needs lead the scientific community to employ SCMs in the development of cement-based materials. However, the effect of Arabian-shield-based NP in the presence of other conventional SCMs on the entire properties of the final products remains an open question. In the present study, the strength and durability properties of high-strength concrete (HSC), which is incorporated with binary and ternary binders, were investigated. Here, SF and NP were employed as SCMs, which replaced the PC content by up to 12 and 25 wt.\%, respectively. Additionally, various isoresponse-prediction methods were developed, and their prediction performance was investigated using hypothesis tests. The prediction model, which was deemed superior according to the aforementioned comparison, was used to investigate the cross interactions of different SCM combinations. Eventually, a blended-cement-based concrete mixture design was established, and its isoresponsive properties were optimized. This design process has shed light on the significance of the categorical factors (i.e., 
$(w / b))$ and continuous factors (i.e., proportions of cement, $\mathrm{SF}$, and NP) on the strength and durability characteristics of the blended-cement-based concrete.

\section{Materials and Methods}

In the current study, type-I PC, which conforms to ASTM C 150 requirements, was used as the primary CM. SF, which conforms to the ASTM C1240 requirements, was employed as SCM. A condensed gray powdered-form SF, which primarily consisted of $\mathrm{SiO}_{2}$ (silica), was prepared by grinding silicon and ferrosilicon alloys. Furthermore, NP, which was obtained from a pozzolan product factory (where the grinding and processing operations of this natural material took place to prepare it for use in cement-based materials), was used as an additional SCM. The physicochemical characteristics of the binders (i.e., PC, SF, and NP) are listed in Table 1. The employed aggregate in the current study was a mixture (plain and crushed) of regionally plenteous material, which originated from mineral calcite (sedimentary rock). Different masses of fine and coarse aggregates were blended to adjust their grain-size distribution within the band recommended by ASTM C136. A chemical admixture (SP, which complied with ASTM C494 type A and F) was utilized to control the slump (i.e., workability indicator) at $120-140 \mathrm{~mm}$ by incorporating SP dosage.

2.1. Mixing, Casting, and Curing of Concrete Mixtures. In the current investigation, 24 concrete mixtures (two typical batches) were prepared. The primary variable of each batch was $(w / b)(0.25$ and 0.4$)$. However, typical SCM replacements were used in every concrete batch. Selection of $(w / b)$ for each series was made to produce normal concrete and HSC. Table 2 lists the summary of the test matrix of the concrete mixture, whereas Figure 1 shows the distribution of the SCMs for every replicate combination (blue circles) in the PC-SF-NP space. Table 2 indicates that SF and NP were used as partial replacement of PC by weight. The selection of 8 to 12 wt. $\%$ of SF and that of 15,20 , and 25 wt. $\%$ of NP were based on the results obtained in $[7,23]$, respectively.

Two concrete mixtures (i.e., Nos. 1 and 13) were used as control specimens. Additionally, 10 concrete mixtures (i.e., Nos. 2-6 and 14-18) contained binary blends of the main binder (i.e., PC) and SF or NP incorporated into these mixtures. The remaining 12 concrete mixtures were ternary concrete mixtures. We must mention that the unit weights of the fine and coarse aggregates for all concrete mixes were 700 and $1040 \mathrm{~kg} / \mathrm{m}^{3}$, respectively. The amounts of water in concrete batches I and II were 141 and $148.4 \mathrm{~kg} / \mathrm{m}^{3}$, respectively. The used aggregates were Saudi Arabian-based normal sand and crushed microcrystalline quartz LS rock. Additionally, a well-graded-based optimization of the grainsize distribution was performed by blending these aggregates. Moreover, a carboxylate ether-based SP that satisfied the ASTM C494 type A and F standard was employed to control the workability of the fresh concrete mixtures (i.e., a slump of $40-80 \mathrm{~mm}$ ). The amount of employed SP was approximately at $5-81 / \mathrm{m}^{3}$.
TABle 1: Physicochemical properties of the CMs.

\begin{tabular}{lccc}
\hline & PC & SF & NP \\
\hline Physical properties & \multicolumn{3}{c}{} \\
Bulk density $\left(\mathrm{kg} / \mathrm{m}^{3}\right)$ & 1362 & $1350-1410$ & $2600-2700$ \\
Specific gravity $\left(\mathrm{g} / \mathrm{m}^{3}\right)$ & 3.14 & 2.0 & - \\
Fineness $\left(\mathrm{m}^{2} \mathrm{~kg}^{-1}\right)$ & 371 & $15-20$ & $<1000$ \\
Average particle size $(\mu \mathrm{m})$ & - & 0.15 & $10-15$ \\
\hline Compressive strength $(\mathrm{MPa})$, & $50 \mathrm{~mm}$ cubes & \\
03 days & 19.4 & - & - \\
07 days & 24.9 & - & - \\
28 days & 35.7 & - & - \\
\hline $\mathrm{Chemical} \mathrm{composition}(\%)$ & & & \\
$\mathrm{SiO}_{2}$ & 20.9 & 90.0 & 42.09 \\
$\mathrm{Al}_{2} \mathrm{O}_{3}$ & 5.2 & 1.0 & 16.43 \\
$\mathrm{Fe}_{2} \mathrm{O}_{3}$ & 2.3 & 1.0 & 14.97 \\
$\mathrm{MgO}_{\mathrm{CaO}}$ & 2.8 & 0.6 & 3.47 \\
$\mathrm{SO}_{3}$ & 64.4 & 0.3 & 9.51 \\
$\mathrm{LOI}_{\mathrm{Insoluble}}$ residue & 2.9 & 0.3 & 0.19 \\
\hline
\end{tabular}

TABLE 2: Cement proportions of the concrete mixtures.

\begin{tabular}{|c|c|c|c|c|}
\hline \multirow{2}{*}{ Batch $(w / b)$} & \multirow{2}{*}{ Mixture no. } & \multicolumn{3}{|c|}{ Proportion of component } \\
\hline & & $\mathrm{PC}$ & SF & NP \\
\hline \multirow{12}{*}{ I $(0.25)$} & 1 & 1.00 & 0.00 & 0.00 \\
\hline & 2 & 0.92 & 0.08 & 0.00 \\
\hline & 3 & 0.88 & 0.12 & 0.00 \\
\hline & 4 & 0.85 & 0.00 & 0.15 \\
\hline & 5 & 0.80 & 0.00 & 0.20 \\
\hline & 6 & 0.75 & 0.00 & 0.25 \\
\hline & 7 & 0.77 & 0.08 & 0.15 \\
\hline & 8 & 0.73 & 0.12 & 0.15 \\
\hline & 9 & 0.72 & 0.08 & 0.20 \\
\hline & 10 & 0.68 & 0.12 & 0.20 \\
\hline & 11 & 0.67 & 0.08 & 0.25 \\
\hline & 12 & 0.63 & 0.12 & 0.25 \\
\hline \multirow{12}{*}{ II $(0.40)$} & 13 & 1.00 & 0.00 & 0.00 \\
\hline & 14 & 0.92 & 0.08 & 0.00 \\
\hline & 15 & 0.88 & 0.12 & 0.00 \\
\hline & 16 & 0.85 & 0.00 & 0.15 \\
\hline & 17 & 0.80 & 0.00 & 0.20 \\
\hline & 18 & 0.75 & 0.00 & 0.25 \\
\hline & 19 & 0.77 & 0.08 & 0.15 \\
\hline & 20 & 0.73 & 0.12 & 0.15 \\
\hline & 21 & 0.72 & 0.08 & 0.20 \\
\hline & 22 & 0.68 & 0.12 & 0.20 \\
\hline & 23 & 0.67 & 0.08 & 0.25 \\
\hline & 24 & 0.63 & 0.12 & 0.25 \\
\hline
\end{tabular}

During the quantification of these amounts, the water content of the SCMs was considered. Casting and curing of the concrete test specimens were performed according to the ASTM C192 specifications. During the concrete curing, the mixtures were fully immersed in a water basin at ambient temperature (i.e., $20 \pm 3^{\circ} \mathrm{C}$ ) up to the testing age (i.e., 28 days of standard curing). Three concrete cubic specimens $\left(150 \times 150 \times 150 \mathrm{~mm}^{3}\right)$ and one cylindrical $(100 \mathrm{~mm} \times 50 \mathrm{~mm}$ (specimen were cast from each concrete mixture. The first set of concrete samples was prepared for measurement of the 


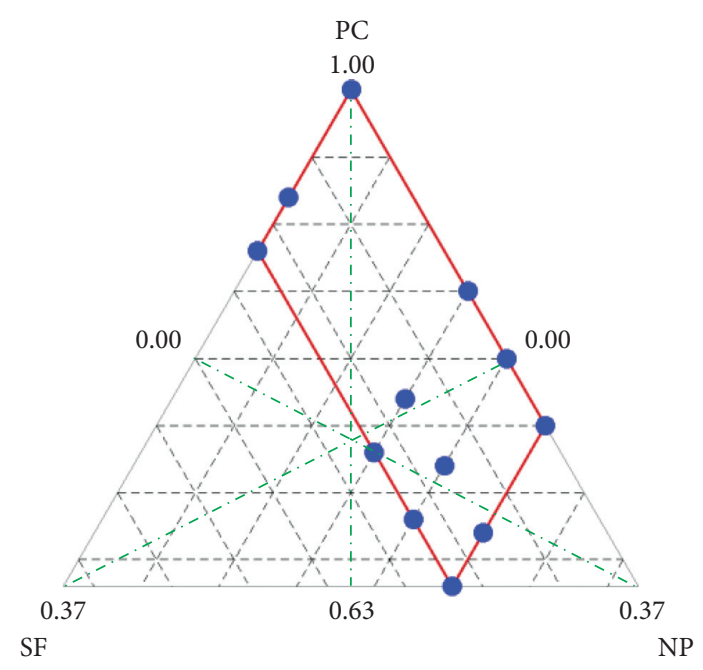

FIGURE 1: Spatial distribution of the SCMs for the concrete mixtures.

compressive strength of the concrete mix, whereas the second set was used for the permeability assessment.

2.2. Testing of Concrete. In the current study, the compressive strengths of all concrete mixtures were physically assessed according to BS 1881-211. The strengths of three replicated samples in every concrete mix were measured on the 28th day after casting. However, the results of only two replicated specimens were sufficient because these results exhibited sensible repeatability (i.e., the percentage difference between two consecutive test runs on the replicates was $\leq 1.0 \%)$. A universal testing machine $(3000-\mathrm{kN}$ load capability) was employed to perform the compressive tests on the concrete samples (67 test runs). Additionally, the loading (under displacement control condition) on every concrete specimen was initiated at no load and slowly increased at a constant rate of $12 \mathrm{~mm} / \mathrm{s}$.

Specimen [100 mm (length) $\times 50 \mathrm{~mm}$ (diameter)] were cast to perform the rapid chloride-permeability test according to ASTM C 1202. In this test, the concrete specimen be placed into the test cell, as shown in Figure 2. Before this process, the concrete sample was taken from the curing tank, dried in an oven for approximately $15 \mathrm{~min}$, only the circumferential side was coated using a fast-thermosetting polymer while two cross section sides are not coated to allow the passage of flow. Then, the concrete specimen was placed into an exhaust dehydrator (test cell), where rarefaction continued for approximately $3 \mathrm{~h}$. Then, water was successfully intermittently injected into the test cell to completely cover the concrete sample. During this time and for approximately $1 \mathrm{~h}$, the exhaust dehydrator was kept operating. The dehydrator was previously switched off, and the concrete sample was water-immersed for $18 \mathrm{~h}$ and finally desiccated using a bibulous paper. The processed concrete sample was subsequently introduced in the test cell using a silicon-oxygen-based water-resistant rubber, which took $45 \mathrm{~min}$ to completely set. Sodium chloride $(\mathrm{NaCl})$ and sodium hydroxide $(\mathrm{NaOH})$ were previously injected into the associated reservoirs, and the $\mathrm{Cl}^{-}$ion concentration was measured. The chloride diffusivity test was run (i.e., the total charge in coulombs that passed was observed) in parallel with the compressive-strength test for two to three replicates. We need to mention that the permeability class of the concrete mixture obtained upon consideration of the average of the previous results was evaluated following the method recommended by ASTM C1202 (Table 3).

2.3. Statistical Analysis. The typical Doe approaches, namely, factorial, response surface, and Taguchi, postulate that all the design related-factors can be autonomously controlled and handled. This control is achievable for a cementitious system-response test, provided that only one or two variables are involved [26]. The mixture design of the current experiment was a special type of Doe because the constituents of the mixture were interdependent [35]. Here, the importance of the various mixture-design variables on the strength and durability features of HSC was studied using the Doe module of Minitab software [36]. This module designated the influential weights of the cross-variables of the mixture to fit an observed response by considering the linear, quadratic, and significantly higher terms. Additionally, the employed statistical methodology allowed evaluation of the response function at any mixture combination within the studied area, and the improved process response could be assessed.

The primary mixture-design method that embodied the categorical and continuous parameters with a predefined design scheme was the SLF method [28]. This method involved replicating (rerunning) the test for the complete spectrum of feasible blends of the components for different mixture categories. On the basis of some preliminary test results, 12 test data points and the associated limits on space were adopted (Figure 1), and two categorical variables were considered $((w / b)$ values of 0.25 and 0.40$)$. The analytically fitted response (12 terms) function of this DOE could be formulated for the three process variables (equation (1)) and replicated for each test category [20, 30, 37]. On the other hand, the RSD system required the formulation of a 


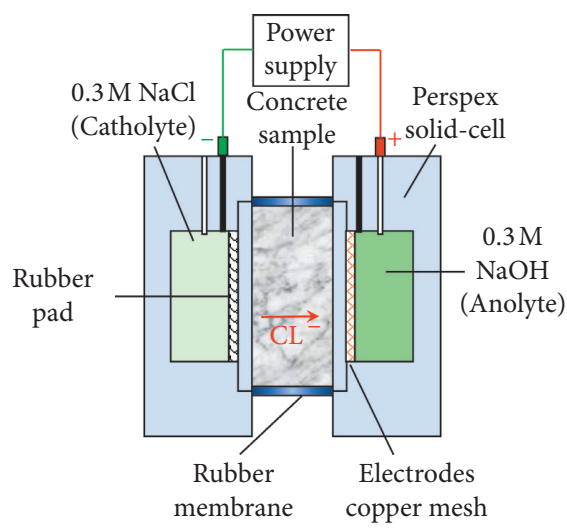

(a)

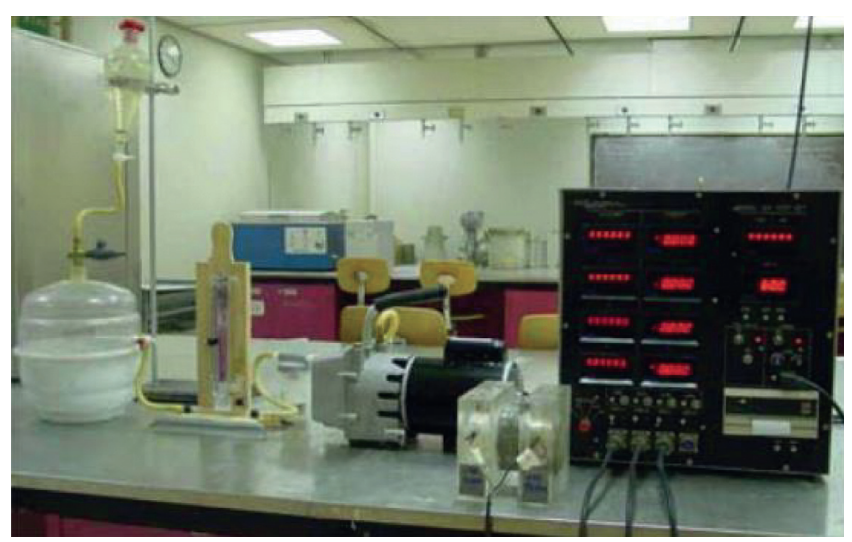

(b)

Figure 2: Chloride-diffusion permeability test. (a) Schematic diagram of the test cell. (b) Test setup.

TABLE 3: Classification of concrete chloride ion penetrability (ASTM C 1202).

\begin{tabular}{lccccc}
\hline Charge passed (Coulombs) & $>4000$ & $2000-4000$ & $1000-2000$ & $100-1000$ & $<100$ \\
\hline Permeability class & High & Moderate & Low & Very low & Negligible \\
\hline
\end{tabular}

regression formula that would be used to describe the response-dependent surface $(\hat{y})$ as a function of the independent variables [1]. In the current study, RSD was also used to formulate the isoresponses of concrete using equation (1). Additionally, analysis of variance (ANOVA) for different predicted isoresponses by the most efficient model was used to identify the significant terms of the polynomial prediction equation:

$$
\widehat{y}=b_{o}+\sum_{i=2}^{i=4} b_{i} x_{i}+\sum_{i=2}^{i=4} b_{i i} x_{i}^{2}+\sum_{i=2}^{i=3} \sum_{j=i+1}^{j=4} b_{i j} x_{i} x_{j}+b_{123} x_{2} x_{3} x_{4}
$$

where $b_{o}, b_{i}, b_{i i}, b_{i j}$, and $b_{123}$ are the constants of the response surface and $x_{2}, x_{3}$, and $x_{4}$ are the PC, SF, and NP components, respectively. We need to point out that a mixture-design method was also developed to investigate the optimum concrete mixture, which includes categorical factor $x_{1}$, i.e., $(w / b)$. Additionally, a prediction-performance-based statistical analysis that employed the paired $t$ and two-sample tests for the mean and standard deviation of the predicted and observed results, respectively, was performed to determine the most reliable prediction model. Moreover, Pareto charts were employed in the present study to examine the level of significance of various binders on the strength and permeability of HPC. These charts employed the $t$-test of the hypothesis (null hypothesis: effect $=0$ ) to investigate the standardized effects in which a reference standard line was plotted to demonstrate the importance and orders of the effects. Notably, the Pareto chart exhibited nonnegative values. Therefore, it could be used as a comparison tool to evaluate the effects. However, it might not be useful in determining the variance of these effects on a specified response [36].

\section{Results and Discussion}

The compressive strength and chloride-permeability results of the 24 concrete mixtures that incorporated SF and NP are listed in Table 4. According to the reproducibility of the result, Table 4 indicates that two to three samples (test runs) have been conducted for a single concrete mixture. Additionally, the prevalence of the property results for each mix from its average is listed in this table using the associated sample standard deviation.

3.1. Strength and Permeability of Concrete with Incorporated $S F$ and NP. The minimum ( $\min$ ), maximum (max), and mean values of the measured compressive strengths of the HPC with $(w / b)$ values of 0.25 and 0.40 and contained SP and NP are shown in Figure 3. As expected, this figure shows that the range (min-max) of the concrete values with 0.40 $(w / b)$ was generally wider than that of the concrete with 0.25 $(w / b)$. This finding was expected because the reproducibility of the concrete strength decreased at higher $(w / b)$ values. Moreover, Figure 3 shows that the 28-day strength of the blended-cement HPC with $0.25(w / b)$ was generally higher than that of the control concrete. However, the strengths of most of the mixtures prepared with $0.40(w / b)$ were below those of their comparable control mixture. The low pozzolanity of NP at relatively higher $(w / b)$ values could have likely led to a reduction in the strength. This result was consistent with that reported by several previous investigators (e.g., [38-40]) for concrete that contained NP. With regard to the binary concrete mixtures (Mix Nos. 2-6) at $0.25(w / b)$, Figure 3 also shows that the mean strengths of the concrete that contained SF (Mix Nos. 2-3 and 14-15) were generally superior to those that contained NP (Mix Nos. 4-6, 16-18). This result could also be attributed to the 
TABLE 4: Summary of the experimental results of concrete mixtures.

\begin{tabular}{|c|c|c|c|c|c|c|c|c|c|c|c|}
\hline \multirow{3}{*}{ Mix no. } & \multicolumn{5}{|c|}{ Compressive strength $(\mathrm{MPa})$} & \multicolumn{5}{|c|}{ Permeability (charge passed, coulombs) } & \multirow{3}{*}{ Class of permeability (ASTM C1202) } \\
\hline & \multicolumn{3}{|c|}{ Test run no. } & \multirow{2}{*}{ Mean } & \multirow{2}{*}{ Std. Dev.* } & \multicolumn{3}{|c|}{ Test run no. } & \multirow{2}{*}{ Mean } & \multirow{2}{*}{ Std. Dev.* } & \\
\hline & 1 & 2 & 3 & & & 1 & 2 & 3 & & & \\
\hline 1 & 82.3 & 82.8 & - & 82.6 & 0.35 & 1877 & 2045 & 1928 & 1950 & 86.13 & Low \\
\hline 2 & 94.1 & 106.9 & 99.7 & 100.2 & 6.42 & 220 & 211 & 219 & 217 & 4.93 & Very low \\
\hline 3 & 98.9 & 90.1 & 92.8 & 93.9 & 4.51 & 215 & 197 & - & 207 & 12.73 & Very low \\
\hline 4 & 91.4 & 92.4 & 89.4 & 91.1 & 1.53 & 2445 & 1852 & 1990 & 2096 & 310.30 & Moderate \\
\hline 5 & 90.9 & 94.0 & 88.7 & 91.2 & 2.66 & 2478 & 2773 & 2953 & 2735 & 239.81 & Moderate \\
\hline 6 & 90.1 & 85.5 & 81.4 & 85.7 & 4.35 & 3098 & 2959 & 2477 & 2845 & 325.91 & Moderate \\
\hline 7 & 92.7 & 98.3 & 89.2 & 93.4 & 4.59 & 195 & 187 & 195 & 192 & 4.62 & Very low \\
\hline 8 & 88.3 & 92.6 & 84.8 & 88.6 & 3.91 & 75 & 74 & - & 75 & 0.71 & Negligible \\
\hline 9 & 94.6 & 89.9 & 93.8 & 92.8 & 2.51 & 205 & 182 & 174 & 187 & 16.09 & Very low \\
\hline 10 & 101.7 & 100.2 & - & 101.0 & 1.06 & 24 & 26 & - & 25 & 1.41 & Negligible \\
\hline 11 & 89.6 & 87.8 & 91.6 & 89.7 & 1.90 & 51 & 39 & - & 45 & 8.49 & Negligible \\
\hline 12 & 85.2 & 95.6 & 90.6 & 90.5 & 5.20 & 71 & 63 & - & 67 & 5.66 & Negligible \\
\hline 13 & 69.5 & 71.8 & 74.2 & 71.8 & 2.35 & 4182 & 4341 & 3988 & 4170 & 176.79 & High \\
\hline 14 & 73.0 & 61.1 & 68.5 & 67.5 & 6.01 & 799 & 957 & 873 & 876 & 79.05 & Very low \\
\hline 15 & 78.8 & 83.7 & 86.4 & 83.0 & 3.85 & 894 & 780 & 833 & 835 & 57.05 & Very low \\
\hline 16 & 62.1 & 59.8 & 60.6 & 60.8 & 1.17 & 6259 & 5346 & 6003 & 5869 & 470.95 & High \\
\hline 17 & 53.6 & 58.6 & 57.9 & 56.7 & 2.71 & 7087 & 6654 & 5532 & 6424 & 802.54 & High \\
\hline 18 & 50.4 & 50.1 & - & 50.3 & 0.21 & 6319 & 7298 & 6482 & 6700 & 524.54 & High \\
\hline 19 & 62.8 & 65.2 & 67.6 & 65.2 & 2.40 & 807 & 909 & 795 & 837 & 62.64 & Very low \\
\hline 20 & 62.0 & 62.5 & - & 62.3 & 0.35 & 269 & 261 & 252 & 261 & 8.50 & Very low \\
\hline 21 & 56.2 & 56.1 & - & 56.2 & 0.07 & 939 & 781 & 983 & 901 & 106.23 & Very low \\
\hline 22 & 63.7 & 69.2 & 68.4 & 67.1 & 2.97 & 101 & 131 & - & 116 & 21.21 & Very low \\
\hline 23 & 63.7 & 65.1 & 69.7 & 66.2 & 3.14 & 186 & 141 & - & 164 & 31.82 & Very low \\
\hline 24 & 60.2 & 65.2 & 58.6 & 61.3 & 3.44 & 319 & 277 & - & 298 & 29.70 & Very low \\
\hline
\end{tabular}

*Standard Deviation.

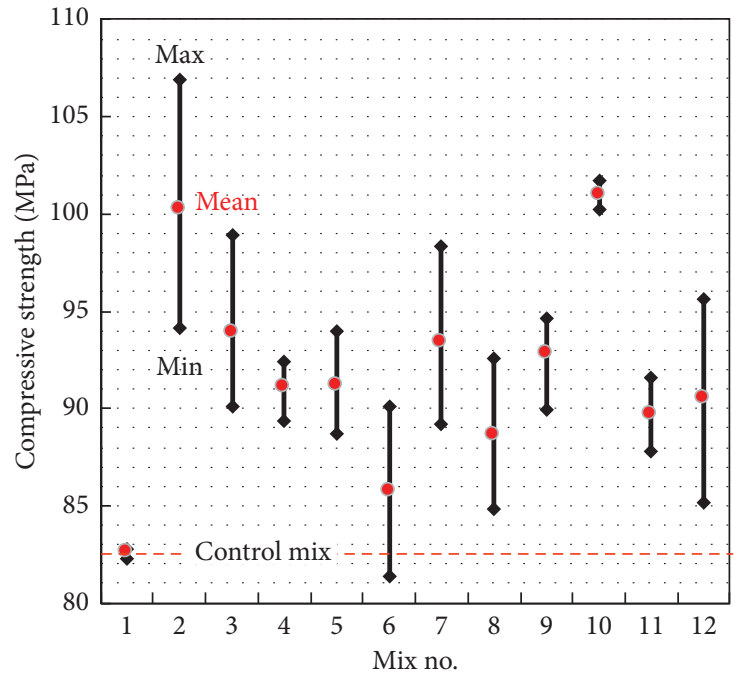

(a)

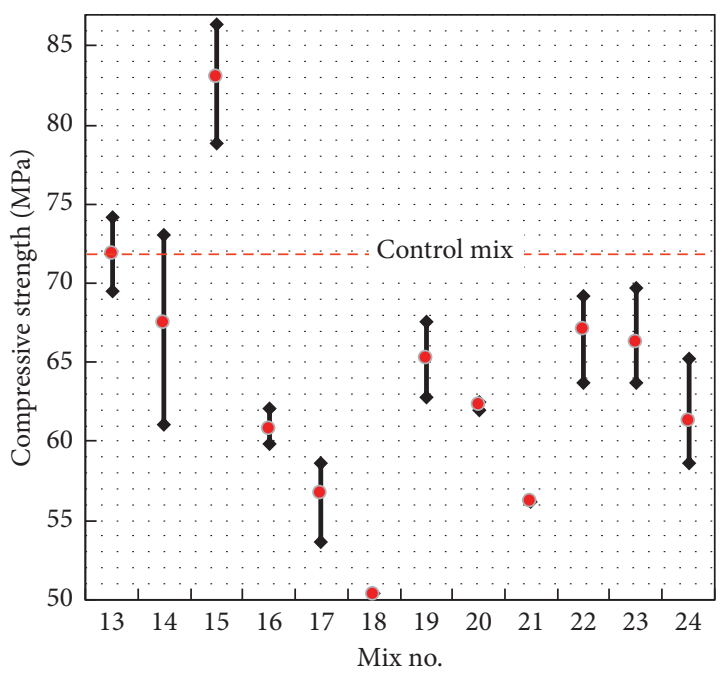

(b)

FiguRE 3: Observed compressive strength ranges of concrete mixtures that incorporate SF and NP: (a) $(w / b)=0.25(\mathrm{~b})(w / b)=0.40$.

higher pozzolanity of SF than that of NP. Moreover, Figure 3 shows the synergistic interactions of SF and NP because the strengths of all the ternary-cement-blended concrete mixtures were higher than those containing PC and NP only. The highest average strength among all concrete mixes at $0.25(w / b)$ was obtained for Mix No. 10 (incorporated with $12 \%$ and $20 \%$ of SF and NP, respectively). However, Mix No.
15 (12\% SF only) possessed the maximum mean strength among the Batch II samples.

Figure 4 shows the experimental results of the chloride diffusivity of HPC that contained SP and NP and developed using the two values of $(w / b)(0.25$ and 0.40$)$. Additionally, Table 4 lists the permeability classification of these concrete mixtures (ASTM C1202, Table 3). For the $0.25(w / b)$ 


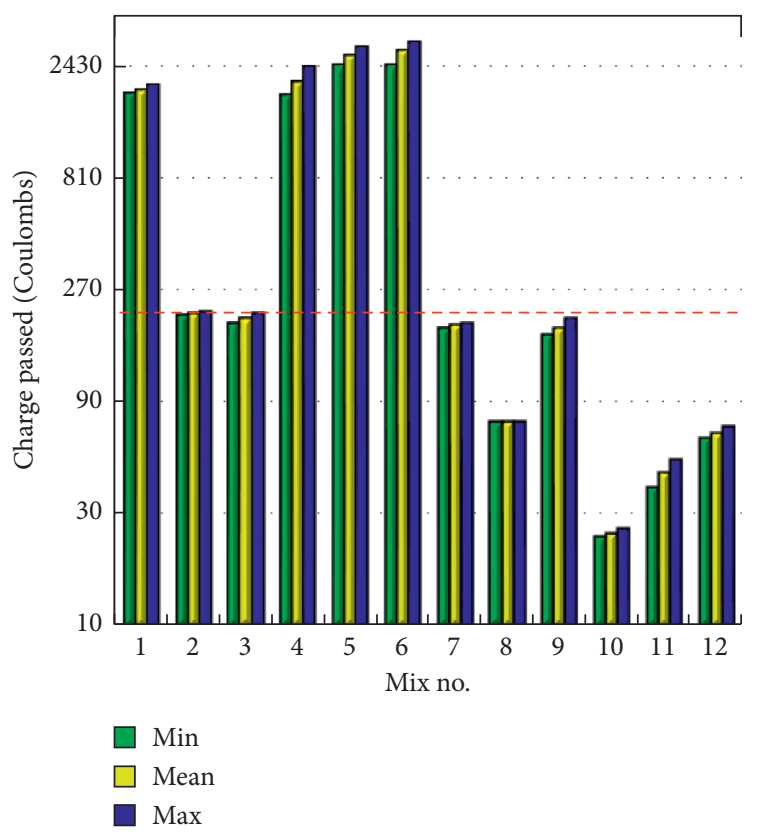

(a)

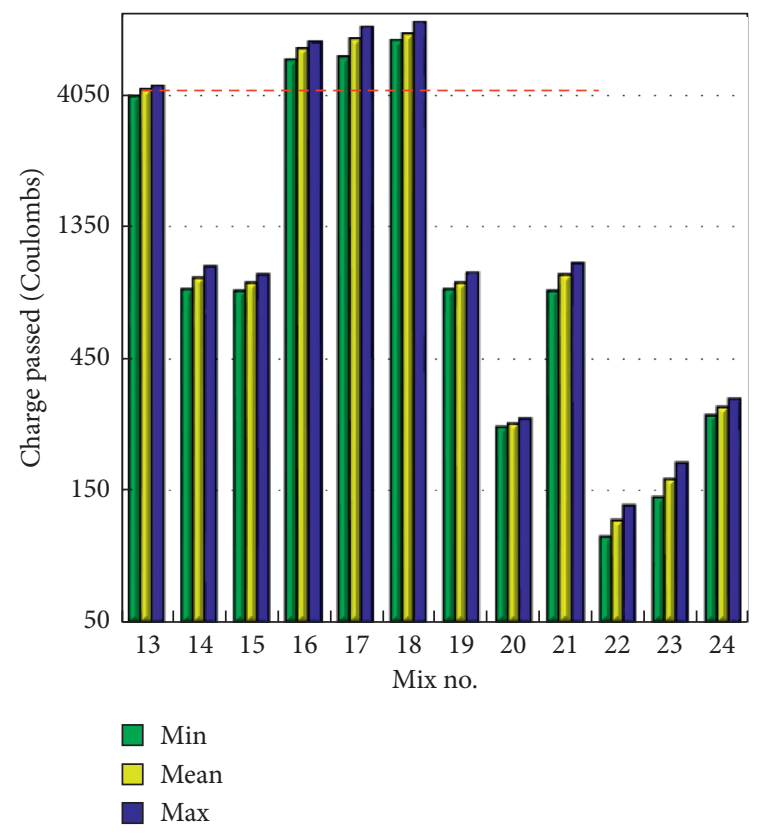

(b)

FiguRE 4: Observed permeability of concrete mixtures that incorporate SF and NP. (a) Batch I $((w / b)=0.25)$ and (b) Batch II $((w / b)$ $=0.40)$.

concrete, these results revealed that the inclusion of SF in the binary blended-cement concrete was more effective than that of NP in lowering the concrete permeability (i.e., Mix Nos. 2 and 3 had "very low" permeabilities, whereas Mix Nos. 4-6 had "moderate" permeabilities). Similarly, NP demonstrated diffusivity influence ("high permeability") that was inferior to that of SF ("very low permeability") for concrete specimens developed at $0.40(w / b)$. This result agreed well with a previous investigation [10], where zeolite (NP) was less effective in lowering the chloride diffusion of concrete compared with SF and MK. Moreover, Figure 4 shows the positive synergy of PC-NP-SF with regard to the permeability of concrete because all ternary-blended-concrete mixtures demonstrated "very low/negligible" diffusivity. This finding agreed with some recently reported research of durability response of natural-based concrete [41-43]. For both $(w / b)$ values, Figure 4 also shows that the lowest chloride permeability was for concrete with $12 \%$ SF and $20 \%$ NP.

In the present study, prediction models for the strength and permeability isoresponses of HPC that contained PC, SF, and NP were developed using two approaches: the first was SLF whereas the second was RSD.
3.2. Isoresponse Prediction. In this study, prediction models for the strength and permeability isoresponses of the HPC incorporating PC, SF, and NP were developed by two approaches; the first was the second-level factorial (SLF) regression, while the second was the response surface design (RSD).

3.2.1. SLF Regression. Here, a $2^{3}$ factorial regression was developed to predict the strength and permeability of concrete (equations (2a), (2b), (3a), and (3b), respectively). The correlation coefficient $\left(R^{2}\right)$, which is a statistical indicator of the robustness of the predicted-observed relationship, is indicated in these equations. The components of the binders (PC, SF, and NP) were considered as factors in this regression system. Figure 5 shows the performance of these prediction models, which demonstrates that the SLF model predicted the strength and permeability with reasonable accuracy compared with the experimental results. Most of the predicted-observed data points that resulted from the SLF model in terms of strength and permeability of the HPC were in the error band of $\pm 5 \%$ and $\pm 10 \%$, respectively. 


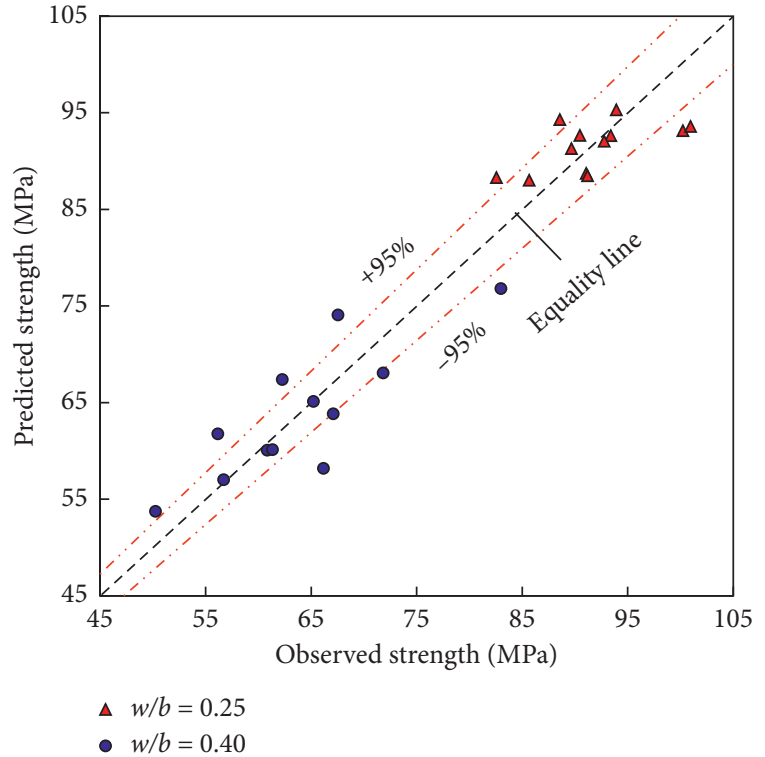

(a)

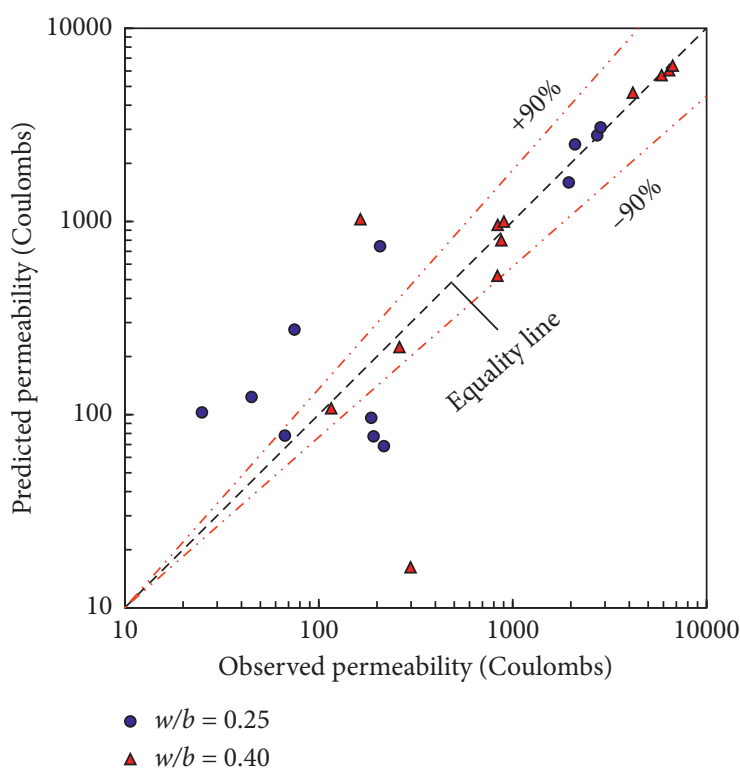

(b)

Figure 5: Predicted versus observed isoresponses (SLF regression). (a) Compressive strength. (b) Permeability.

$$
\begin{aligned}
f_{0.25}= & 95.77+4.23 x_{2}+1.17 x_{3}+10.3 x_{2} x_{3} \\
& +4.57 x_{2} x_{4}+7.36 x_{3} x_{4}-8.25 x_{2} x_{3} x_{4}, \\
R^{2}= & 61.24 \%, \\
(w / b)= & 0.25 \\
f_{0.40}= & 62.09+11.58 x_{2}+7.47 x_{3} \\
& -6.1 x_{2} x_{3}-3.92 x_{2} x_{4}-4.5 x_{3} x_{4} \\
& -0.9 x_{2} x_{3} x_{4}, \\
R^{2}= & 74.37 \%, \\
(w / b)= & 0.40 \\
\mu_{0.25}= & 365-250 x_{2}-1139.1 x_{3}-2462 x_{2} x_{3} \\
& -146 x_{2} x_{4}-2010 x_{3} x_{4}+95 x_{2} x_{3} x_{4}, \\
R^{2}= & 98.90 \%, \\
(w / b)= & 0.25 \\
\mu_{0.40}= & 1478-303 x_{2}-2846 x_{3}-5059 x_{2} x_{3} \\
& +266 x_{2} x_{4}-4142 x_{3} x_{4}-501 x_{2} x_{3} x_{4}, \\
R^{2}= & 99.44 \%, \\
(w / b)= & 0.40 .
\end{aligned}
$$

3.2.2. RSD Regression. Equations (4a), (4b), (5a), and (5b) indicate the developed strength and permeability models using RSD. The prediction capability of these models is shown in Figure 6, which shows that the predicted results by RSD were reasonably close to the test results. With respect to the SLF model, the predicted-observed results obtained by

RSD in terms of the strength and permeability of HPC were within the accuracy range of $\pm 95 \%$ and $\pm 90 \%$, respectively.

$$
\begin{aligned}
f_{0.25}= & 91.69+1.08 x_{2}+3.63 x_{3}-1.35 x_{2}^{2}-0.24 x_{3}^{2} \\
& +0.74 x_{4}^{2}, \\
R^{2}= & 92.33 \% \\
(w / b)= & 0.25 \\
f_{0.40}= & 65.32+11.47 x_{2}+7.86 x_{3}-1.35 x_{2}^{2}-0.24 x_{3}^{2} \\
& +0.74 x_{4}^{2}, \\
R^{2}= & 92.33 \% \\
(w / b)= & 0.40, \\
& \mu_{0.25}=125-244 x_{2}-1078 x_{3}-1315 x_{2}^{2} \\
& +1371 x_{3}^{2}+575 x_{4}^{2}, \\
& R^{2}=97.71 \%, \\
& (w / b)=0.25, \\
\mu_{0.40}= & 1679-454 x_{2}-2780 x_{3}-1315 x_{2}^{2} \\
& +1371 x_{3}^{2}+575 x_{4}^{2}, \\
R^{2}= & 97.71 \%, \\
(w / b)= & 0.40 .
\end{aligned}
$$

3.2.3. Prediction Performance-Based Analysis of the SLF and RSD Models. Table 5 lists the results of the paired $t$ - and two-sample tests for the averages and standard deviations of the predicted and observed results obtained by the SLF and RSD models, respectively. In these tests, the null hypothesis 


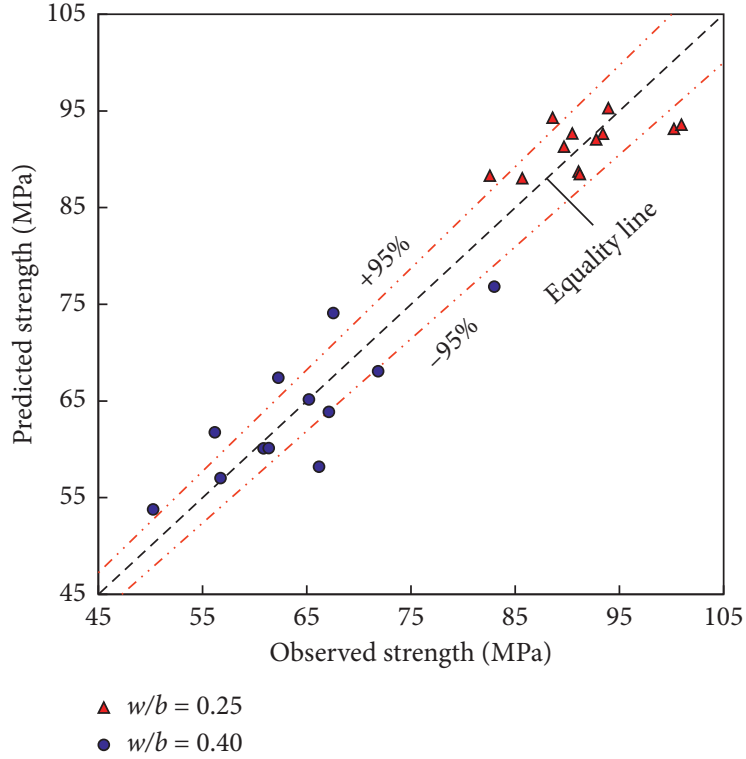

(a)

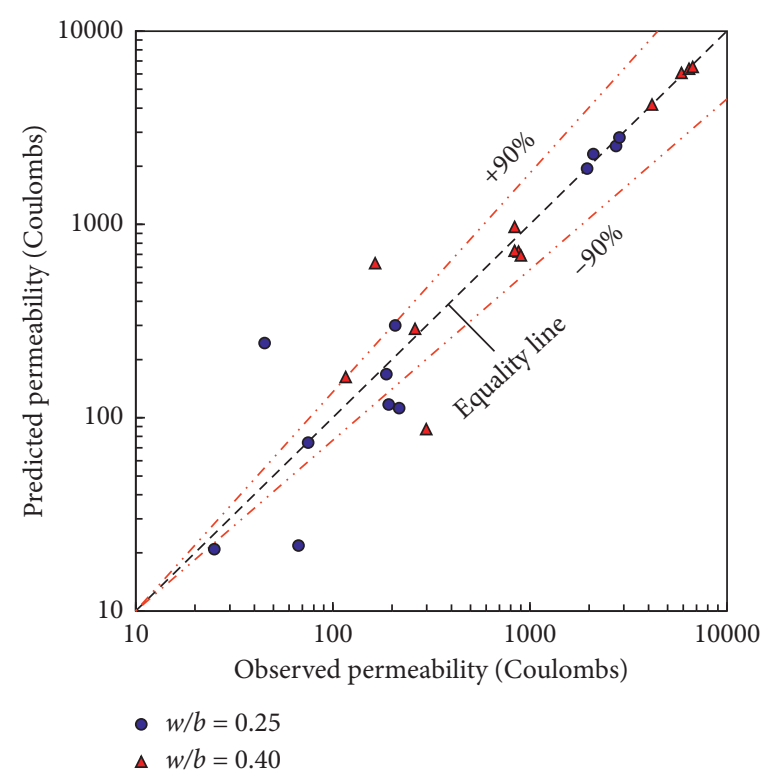

(b)

Figure 6: Predicted versus observed isoresponse (RSD). (a) Compressive strength. (b) Permeability.

Table 5: Paired t- and two-sample tests for the predicted and observed results.

\begin{tabular}{|c|c|c|c|c|c|c|c|c|c|c|}
\hline \multirow[t]{2}{*}{ Regression method } & \multirow[t]{2}{*}{ Variable } & \multirow[t]{2}{*}{ Eq. } & \multirow[t]{2}{*}{$W / b$} & \multirow[t]{2}{*}{ Result } & \multirow[t]{2}{*}{ Mean (MPa) } & \multirow[t]{2}{*}{ Std. Dev. (MPa) } & \multicolumn{2}{|c|}{$\begin{array}{l}95 \% \text { confidence } \\
\text { interval of } \\
\text { difference }\end{array}$} & \multicolumn{2}{|c|}{$p$-value } \\
\hline & & & & & & & Lower & Upper & Mean & Std. Dev. \\
\hline \multirow{4}{*}{ SLF } & \multirow{2}{*}{ Compressive strength } & 1a & 0.25 & $\begin{array}{l}\text { Observed } \\
\text { Predicted }\end{array}$ & $\begin{array}{l}91.71 \\
91.71\end{array}$ & $\begin{array}{l}5.25 \\
4.11\end{array}$ & -2.08 & 2.08 & 1.000 & 0.238 \\
\hline & & $1 b$ & 0.40 & $\begin{array}{l}\text { Observed } \\
\text { Predicted }\end{array}$ & $\begin{array}{l}64.03 \\
64.03\end{array}$ & $\begin{array}{l}8.39 \\
7.23\end{array}$ & -2.70 & 2.70 & 1.000 & 0.334 \\
\hline & \multirow{2}{*}{ Permeability } & $2 \mathrm{a}$ & 0.25 & $\begin{array}{l}\text { Observed } \\
\text { Predicted }\end{array}$ & $\begin{array}{l}886.75 \\
890.38\end{array}$ & $\begin{array}{l}1148.50 \\
1139.10\end{array}$ & -78.54 & 71.70 & 0.917 & 0.490 \\
\hline & & $2 b$ & 0.40 & $\begin{array}{l}\text { Observed } \\
\text { Predicted }\end{array}$ & $\begin{array}{l}2287.6 \\
2287.6\end{array}$ & $\begin{array}{l}2669.2 \\
2667.7\end{array}$ & -126.82 & -126.82 & -126.82 & 0.496 \\
\hline \multirow{4}{*}{ RSD } & \multirow{2}{*}{ Compressive strength } & $3 a$ & 0.25 & $\begin{array}{l}\text { Observed } \\
\text { Predicted }\end{array}$ & $\begin{array}{l}91.71 \\
91.54\end{array}$ & $\begin{array}{l}5.25 \\
2.55\end{array}$ & -2.54 & 2.87 & 0.895 & 0.027 \\
\hline & & $3 b$ & 0.40 & $\begin{array}{l}\text { Observed } \\
\text { Predicted }\end{array}$ & $\begin{array}{l}64.03 \\
63.86\end{array}$ & $\begin{array}{l}8.39 \\
6.90\end{array}$ & -2.81 & 3.14 & 0.905 & 0.287 \\
\hline & \multirow{2}{*}{ Permeability } & $4 \mathrm{a}$ & 0.25 & $\begin{array}{l}\text { Observed } \\
\text { Predicted }\end{array}$ & $\begin{array}{l}886.75 \\
960.75\end{array}$ & $\begin{array}{l}1148.5 \\
1193.0\end{array}$ & -230.90 & 82.90 & 0.322 & 0.546 \\
\hline & & $4 \mathrm{~b}$ & 0.40 & $\begin{array}{l}\text { Observed } \\
\text { Predicted }\end{array}$ & $\begin{array}{l}2287.6 \\
2290.3\end{array}$ & $\begin{array}{l}2669.2 \\
2576.7\end{array}$ & -230.28 & 224.87 & 0.980 & 0.453 \\
\hline
\end{tabular}

illustrated that the mean and standard deviation of each model were notably different from those of the observed results. Table 5 illustrates that no statistical evidence existed to assert that the mean and standard deviations of the predicted strength or permeability were different from those of the test results at a $5 \%$ level of confidence $(p>0.05)$ except for one specimen. For this specimen, the standard deviation of the observed compressive strength was significantly higher than that obtained by the RSD model. We could conclude from this analysis that both SLF and RSD could be reliably used to generate the strength and permeability data of HPC.

In addition, paired $t$-test (Table 6) at a $5 \%$ level of significance was performed to investigate the relationship between MSE of the predictions of the strength and permeability as obtained by SLF and RSD in all samples (i.e., 24 concrete mixtures). For both the strength and permeability predictions, this hypothesis test revealed that MSE obtained by SLF was notably less than that yielded by RSD because its $p$ value was less than the level of significance (i.e., $<0.05$ ). 
TABLE 6: Paired $t$-test for the MSE of RSD predictions of strength and permeability.

\begin{tabular}{|c|c|c|c|c|c|c|c|}
\hline \multicolumn{3}{|c|}{ Paired-differences } & \multicolumn{2}{|c|}{ SLF } & \multicolumn{2}{|c|}{ RSD } & \multirow{2}{*}{$p$-value } \\
\hline Absolute error mean & 95\% upper bound & Std. Dev. & Mean & Std. Dev. & Mean & Std. Dev. & \\
\hline \multicolumn{8}{|c|}{ Compressive strength $(\mathrm{MPa})$} \\
\hline 5.20 & -0.704 & 12.867 & 13.16 & 18.43 & 18.368 & 20.0 & 0.030 \\
\hline Chloride permeability & rge passed, coulom & & & & & & \\
\hline
\end{tabular}

This result established the predominance of the SLF model over the RSD model. Therefore, it was subsequently used to investigate the effect of various binders on the strength and durability of HPC.

3.3. Effect of Binders on Permeability of HPC. According to the credibility of the SLF model (equation (3a) and (3b)) and the established statistical importance, the effect of each of the binders on the strength of HPC was assessed. Figure 7 shows the Pareto chart of the standardized permeability effect at the two $(w / b)$ values, which is plotted using the SLF model (equation (5a) and (5b)). Figure 7 consistently shows that the SF, SF-NP, and PC-NP interactions demonstrated notable statistical importance at a significance level of $5 \%$ on the permeability of HPC at the two $(w / b)$ values. All factors (interaction terms) crossed the reference line at 2.57. Future studies will explore the significance of other influential factors (e.g., $(w / b)$, age of concrete, and chemical admixtures).

3.4. Design of Mixture. The design-of-mixture models for the 28-day compressive strength, i.e., $f$ (in $\mathrm{MPa}$ ) and permeability $\mu$ (in coulombs), are expressed by equations (6) and (7), respectively. We should note that in these models, the $w / b$ value was included as a coded process variable $\left(x_{1}\right)$, and its terms with no statistical significance were excluded. Moreover, Figures 8 and 9 show the graphical representations of the isoresponses resulting from these equations. These figures show that the space circumscribed by the broken lines constitutes the limits of the PC-SF-NP space (Figure 1) in this study. Figure 8 shows that NP had little influence on the compressive strength of HPC with a $(w / b)$ value of 0.25 . Under this $(w / b)$ value, the replacement of PC by $0 \%-15 \%$ NP by weight and $10 \%-15 \%$ SF resulted in the maximum strength response surface $(>95 \mathrm{MPa})$. Additionally, Figure 9 shows that the strength of concrete with a $(w / b)$ value of 0.40 notably decreased as the NP proportion increased. A dramatic decrease in the concrete strength at this $(w / b)$ value was observed at the NP replacement level of more than $15 \%$. These findings were in complete agreement with those reported by Shannag [39] for HPC that incorporated SF and NP with $(w / b)=0.35$.

$$
\begin{gathered}
f=78.19 x_{2}+57 x_{3}+55 x_{4}+106 x_{2} x_{3} \\
-8 x_{2} x_{4}+19 x_{3} x_{4}-7.14 x_{1} x_{2} \\
+568 x_{1} x_{3}+79 x_{1} x_{4}-672 x_{1} x_{2} x_{3} \\
\quad-166 x_{1} x_{2} x_{4}-655 x_{1} x_{3} x_{4}, \\
R^{2}=93.53 \%, \\
\mu=3114 x_{2}+283801 x_{3}+8396 x_{4} \\
-342448 x_{2} x_{3}+1618 x_{2} x_{4}-417664 x_{3} x_{4} \\
+1193 x_{1} x_{2}+101709 x_{1} x_{3}-1388 x_{1} x_{4} \\
-122370 x_{1} x_{2} x_{3}+7462 x_{1} x_{2} x_{4}-153229 x_{1} x_{3} x_{4}, \\
R^{2}=99.24 \% .
\end{gathered}
$$

Moreover, the surface response and contour graphs of the concrete permeability isoresponses at $w / b$ values of 0.25 and 0.40 obtained from equation (7) are shown in Figures 10 and 11, respectively. Both figures revealed the insignificant influence of NP on the chloride diffusivity of concrete compared with that of SF. This insignificant effect of NP could be attributed to its relatively large particle size. Another possible cause for this effect could be the twisted NP microstructure, as suggested by Valipour et al. [10].

Additionally, the previously developed mixture-design models (equations (6) and (7)) were used to optimize the binder components of HPC, which targeted the maximum strength and minimum permeability. The results of this optimization are shown in Figures 12 and 13. The space with red-border lines in these figures constitutes the studied zone in the current investigation of the cement-based blends (i.e., upper/lower boundaries of PC, SF, and NP). The optimum PC, SP, and NP proportions of HPC with a $(w / b)$ value of 0.25 (Figure 12(a)) to obtain the highest strength $(92-95 \mathrm{MPa})$ were probably in the ranges of $60 \%-75 \%$, $5 \%-10 \%$, and $20 \%-30 \%$, respectively. The corresponding values for the highest strength $(65-70 \mathrm{MPa})$ of $\mathrm{HPC}$ with a $(w / b)$ value of 0.40 (Figure $12(\mathrm{~b})$ ) could be $73 \%-82 \%, 8 \%-$ $12 \%$, and $10 \%-15 \%$, respectively.

The optimum proportions of PC, SP, and NP (Figure 13(a)) for HPC with a $(w / b)$ value of 0.25 that could minimize its chloride diffusivity (100-1000 coulombs) could 


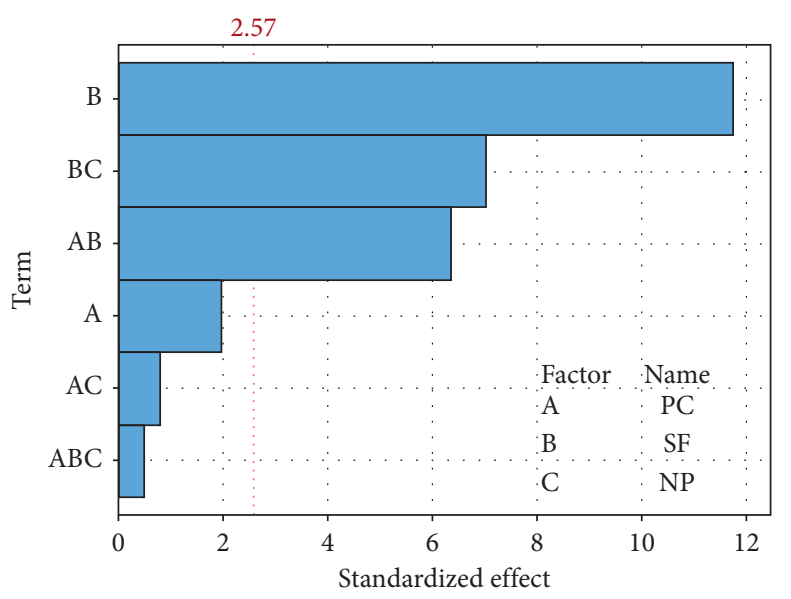

(a)

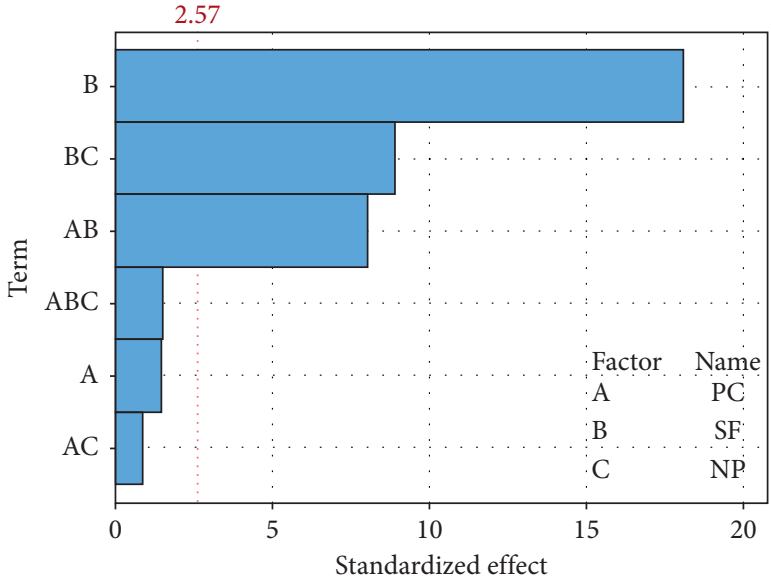

(b)

Figure 7: Pareto chart of permeability standardized effects $(\alpha=0.05)$. (a) $(w / b)=0.25$. (b) $(w / b)=0.40$.

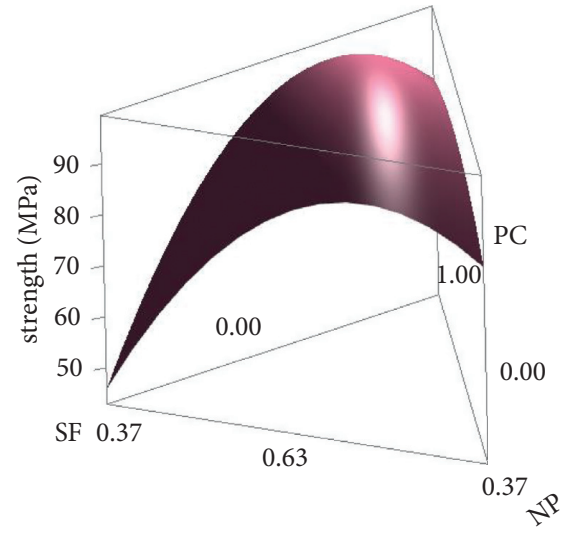

(a)

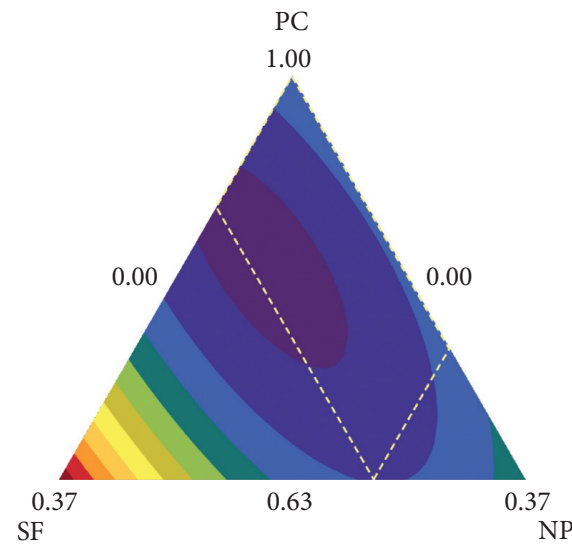

(b)

FiguRE 8: Strength isoresponse of concrete that incorporates a blend of binders $((w / b)=0.25)$. (a) Surface. (b) Contours.

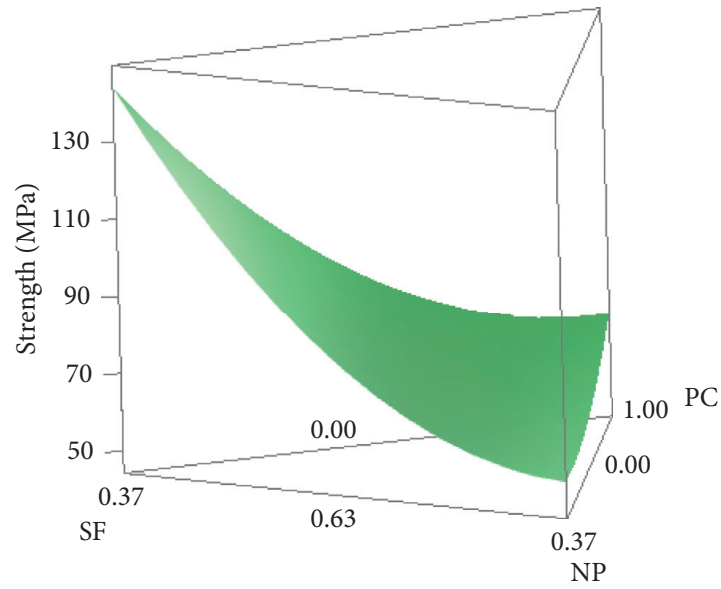

(a)

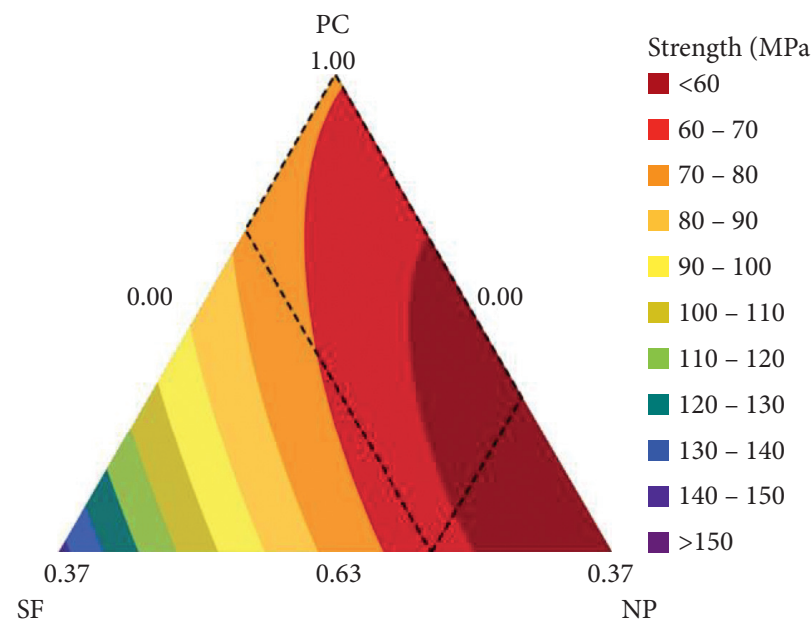

(b)

Figure 9: Strength isoresponse of concrete that incorporates a blend of binders $((w / b)=0.40)$. (a) Surface. (b) Contours. 


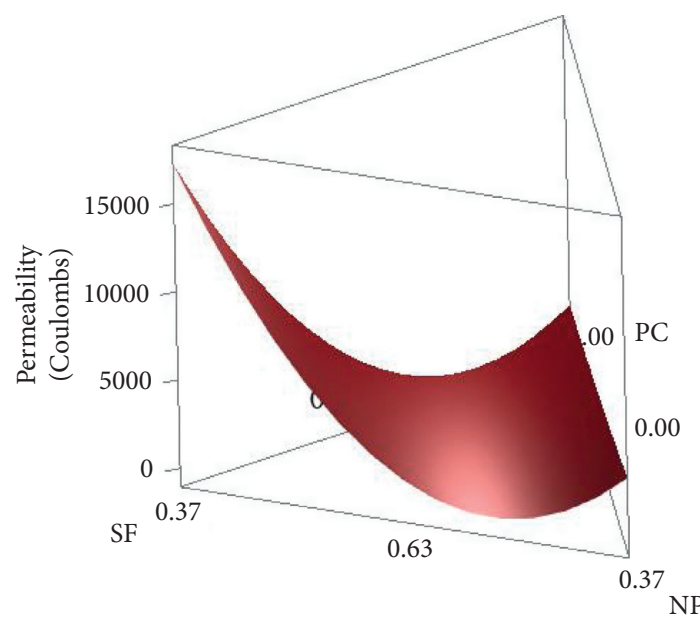

(a)

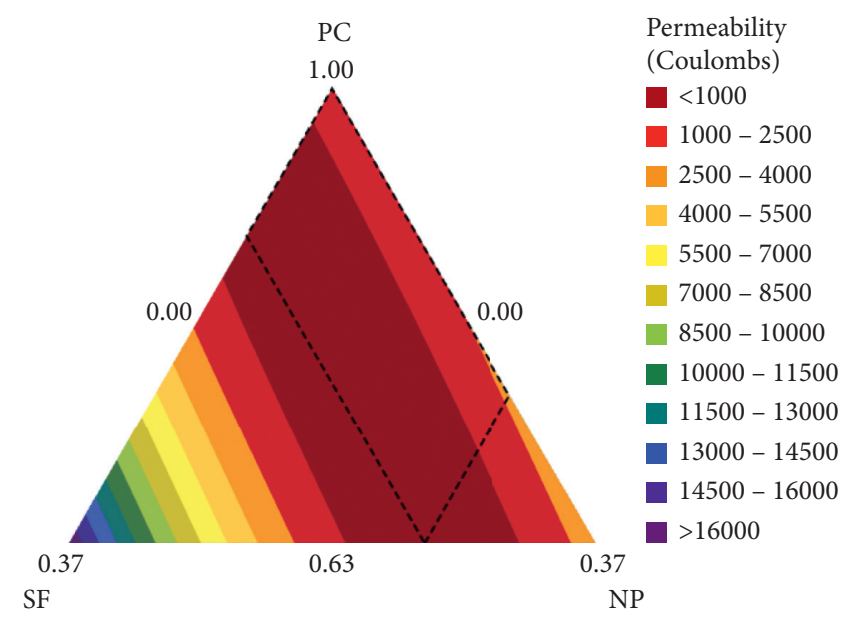

(b)

FIgURE 10: Permeability isoresponse of concrete that incorporates a blend of binders $(w / b)=0.25$ ). (a) Surface. (b) Contours.

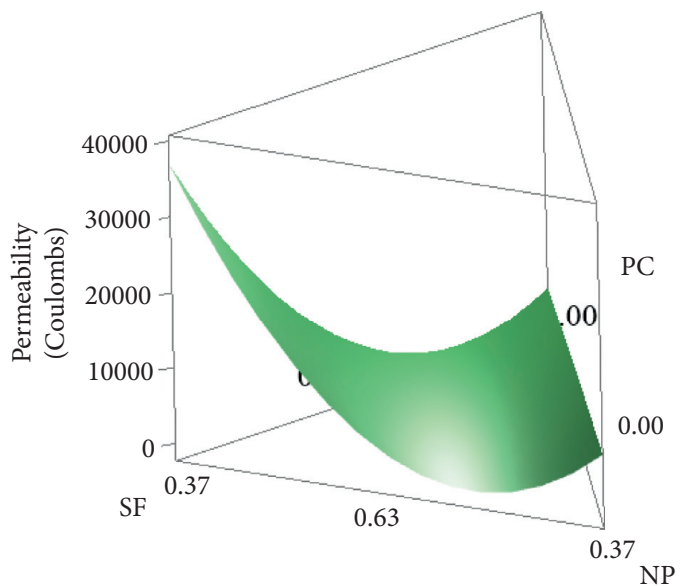

(a)

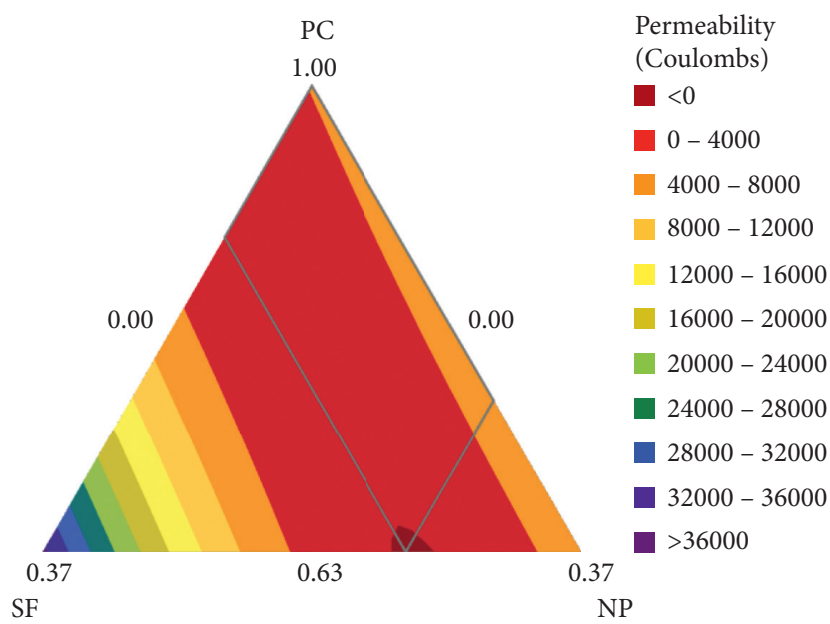

(b)

FIgURE 11: Permeability isoresponse of concrete that incorporates a blend of binders $(w / b)=0.40$ ). (a) Surface. (b) Contours.

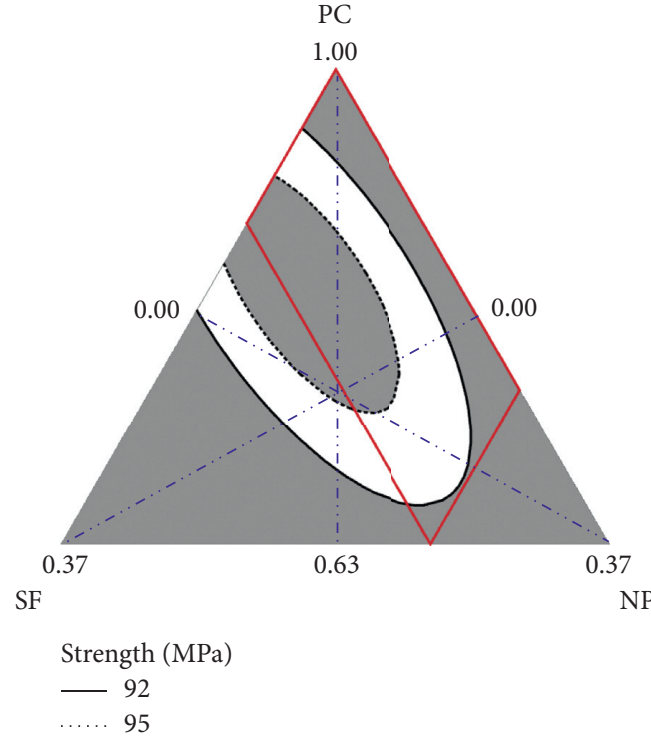

(a)

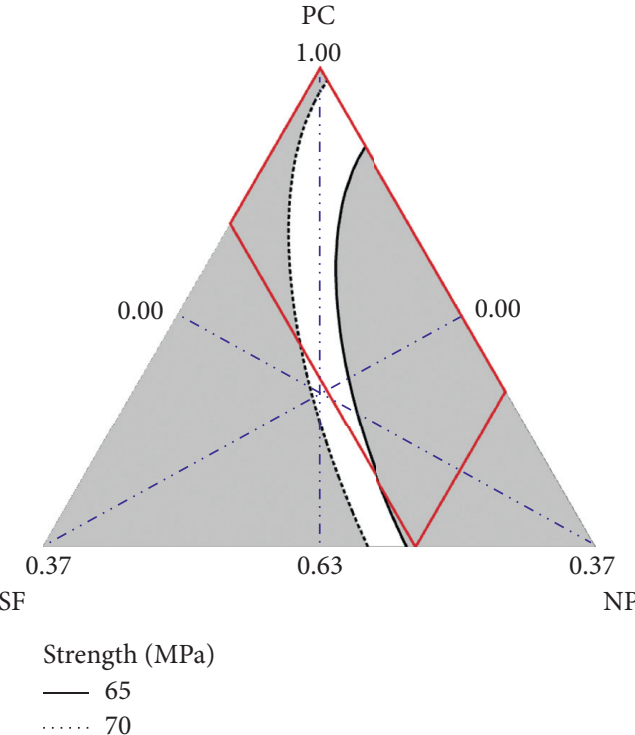

(b)

FIGURE 12: Strength optimization of concrete that incorporates a blend of binders. (a) $(w / b)=0.25$. (b) $(w / b)=0.40$. 


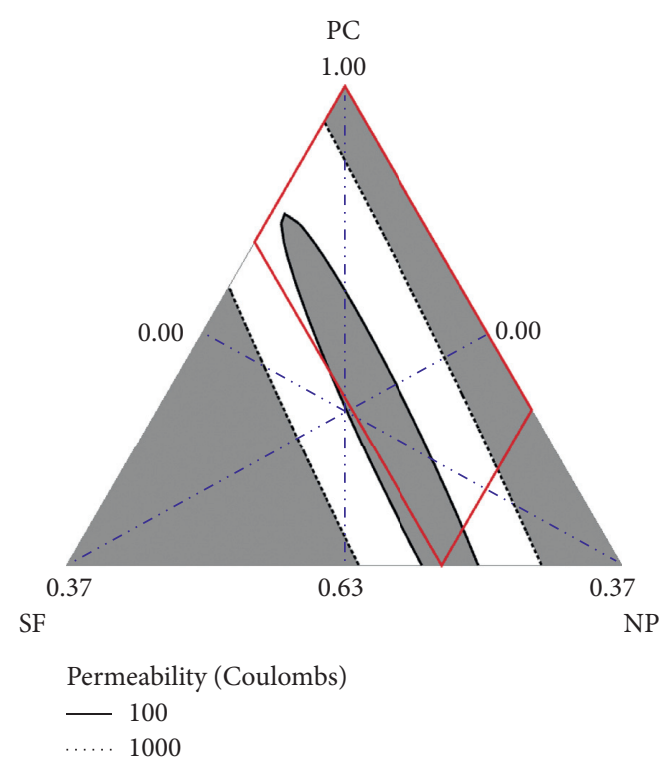

(a)

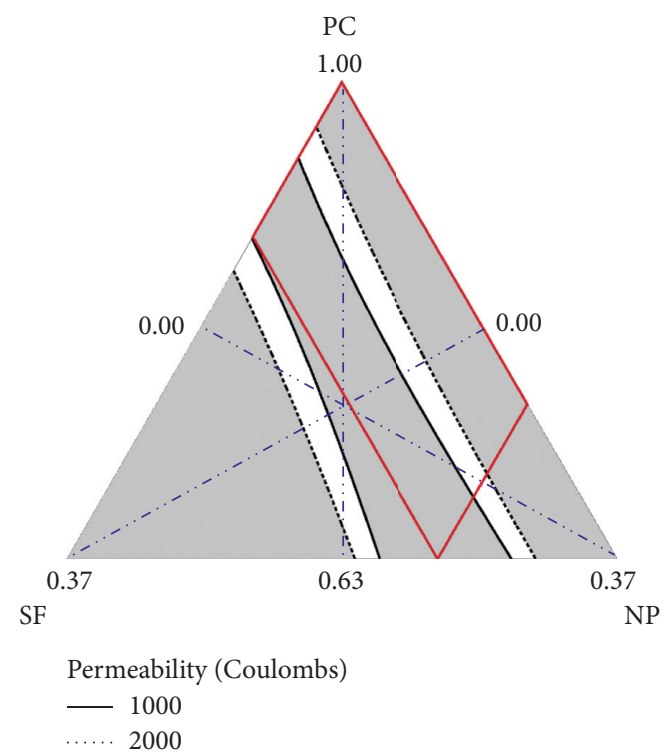

(b)

Figure 13: Permeability optimization of concrete that incorporates a blend of binders. $(a)(w / b)=0.25 .(b)(w / b)=0.40$.

be $60 \%-75 \%, 5 \%-10 \%$, and $20 \%-30 \%$, respectively. Similarly, Figure 13(b) shows that the corresponding figures for the minimum permeability (1000-2000 coulombs) of HPC with a $(w / b)$ value of 0.40 could be $63 \%-82 \%, 8 \%-12 \%$, and $20 \%-25 \%$, respectively.

\section{Conclusions and Perspective}

In this study, cementitious-material proportions were designed for use in HPC that contained SF and NP using a performance-based statistical approach. Two isoresponseprediction models for this concrete were developed and validated based on SLF and RSD. Statistical test of hypotheses was employed to investigate the plausibility and hierarchy of relevance of these models. The model that demonstrated the best prediction performance was used to further investigate the significance and interactions of the PC, SF, and NP blends. A mixture-design approach was established and utilized to optimize the isoresponsive properties of the blended-cement HPC. According to the present study, the following conclusions may be drawn, whose validity and applicability may be limited to the materials and testing conditions reported herein.

(i) The strength of the PC-SF-based HPC with a $(w / b)$ value of 0.25 was generally higher than that of the PC-NP-based HPC. This conclusion indicated the pozzolanic superiority of SF compared with that of NP. At a low $(w / b)$ value, SF and NP exhibited synergistic interactions because the strength of the ternary-blended-cement HPC was generally higher than that of the comparable binary blend.

(ii) NP was less effective in lowering the chloride diffusion of concrete compared with SF. In addition, a positive synergy among $\mathrm{PC}, \mathrm{NP}$, and $\mathrm{SF}$ was also observed in the permeability of HPC. The lowest chloride permeability was observed for the concrete at various $(w / b)$ values with $12 \%$ SF and $20 \%$ NP.

(iii) The optimum SF and NP proportions that could maximize the strength and minimize the diffusivity of HPC with a $(w / b)$ value of 0.25 were $12 \%$ and $20 \%$, respectively. The design-of-mixture analysis showed that a replacement of PC with $0 \%-15 \mathrm{wt} . \%$ of NP and the introduction of $10 \%-15 \%$ of SF resulted in the maximum strength response surface $(>95 \mathrm{MPa}$ ) with a $w / b$ value of 0.25 . This analysis also illustrated that SF is more influential in enhancing the chloride diffusivity compared with NP.

(iv) The SLF and the RSD models predicted the strength and permeability of HPC with reasonable accuracy compared with the experimental results. Most of the predicted-observed data points from both models for strength and permeability of HPC were in the error band of $\pm 5 \%$ and $\pm 10 \%$, respectively.

(v) The paired-t and two-sample statistical tests of the hypothesis for these models indicated that no statistical evidence existed to show that the mean and standard deviation of the predicted strength and permeability were different from the test results at the $5 \%$ level of confidence $(p>0.05)$. These tests of the hypothesis established the reliability of SLF and RSD models for predicting the strength and permeability of HPC.

(vi) The paired $t$-test at the $5 \%$ level of significance revealed that MSE obtained by SLF was notably less 
than that yielded by RSD. This result proved the predominance of SLF compared with RSD. Therefore, the SLF model was employed to investigate the effect of various binders and their interactions on the strength and permeability isoresponses of HPC.

(vii) A standardized Pareto chart indicated that PC and SF were relatively very close to the significant scale of the HPC with $(w / b)=0.40$. In the case of a low $(w / b)$ value, the maximum influence was observed for the ternary blend of binders.

(viii) The SF, SF-NP, and PC-NP interactions demonstrated notable statistical importance on the permeability of the HPC.

(ix) Future investigations are required to incorporate $(w / b)$ in the SLF model as a continuous variable because it would have the most significant effect on the strength of concrete.

(x) Future studies are required to explore the performance-based statistical significance of other influential factors (e.g., $(w / b)$, age of concrete, and chemical admixtures) on the properties of blended-cement concrete.

\section{Data Availability}

The data are included within the article.

\section{Conflicts of Interest}

The authors declare that there are no conflicts of interest related to this study.

\section{Acknowledgments}

The authors extend their appreciation to the Deanship of Scientific Research at King Saud University for funding the work through the research group project (No. RG1441-421). The authors also thank the Deanship of Scientific Research and RSSU at King Saud University for their technical support. This work was supported by the Deanship of Scientific Research (grant number RG-1441-421), King Saud University.

\section{References}

[1] M. A. B. Promentilla, N. H. Thang, P. T. Kien, H. Hinode, F. T. Bacani, and S. M. Gallardo, "Optimizing ternary-blended geopolymers with multi-response surface analysis," Waste and Biomass Valorization, vol. 7, no. 4, pp. 929-939, 2016.

[2] N. Bheel, S. A. Abbasi, P. Awoyera et al., "Fresh and hardened properties of concrete incorporating binary blend of metakaolin and ground granulated blast furnace slag as supplementary cementitious material," Advances in Civil Engineering, vol. 2020, Article ID 8851030, , 2020.

[3] A. Hasanbeigi, W. Morrow, E. Masanet, J. Sathaye, and T. Xu, "Energy efficiency improvement and $\mathrm{CO} 2$ emission reduction opportunities in the cement industry in China," Energy Policy, vol. 57, pp. 287-297, 2013.
[4] D. Patel, R. Shrivastava, R. P. Tiwari, and R. K. Yadav, "Properties of cement mortar in substitution with waste fine glass powder and environmental impact study," Journal of Building Engineering, vol. 27, Article ID 100940, 2020.

[5] F. Batool, A. Masood, and M. Ali, "Characterization of sugarcane bagasse ash as pozzolan and influence on concrete properties," Arabian Journal for Science and Engineering, vol. 45, no. 5, pp. 3891-3900, 2020.

[6] H.-J. Shau, T.-Y. Liu, P.-H. Chen, and N. N. S. Chou, "Sustainability practices for the Suhua highway improvement project in Taiwan," International Journal of Civil Engineering, vol. 17, no. 10, pp. 1631-1641, 2019.

[7] M. I. Khan and C. J. Lynsdale, "Strength, permeability, and carbonation of high-performance concrete," Cement and Concrete Research, vol. 32, no. 1, pp. 123-131, 2002.

[8] M. Thomas, Supplementary Cementing Materials in Concrete, CRC press, Boca Raton, FL, USA, 2013.

[9] S. Choucha, A. Benyahia, M. Ghrici, and M. S. Mansour, "Effect of natural pozzolan content on the properties of engineered cementitious composites as repair material," Frontiers of Structural and Civil Engineering, vol. 12, no. 3, pp. 261-269, 2018.

[10] M. Valipour, F. Pargar, M. Shekarchi, and S. Khani, "Comparing a natural pozzolan, zeolite, to metakaolin and silica fume in terms of their effect on the durability characteristics of concrete: a laboratory study," Construction and Building Materials, vol. 41, pp. 879-888, 2013.

[11] M. Radlinski and J. Olek, "Investigation into the synergistic effects in ternary cementitious systems containing portland cement, fly ash and silica fume," Cement and Concrete Composites, vol. 34, no. 4, pp. 451-459, 2012.

[12] E. Ghafari, S. Ghahari, D. Feys, K. Khayat, A. Baig, and R. Ferron, "Admixture compatibility with natural supplementary cementitious materials," Cement and Concrete Composites, vol. 112, Article ID 103683, 2020.

[13] M. Valipour, F. Pargar, M. Shekarchi, S. Khani, and M. Moradian, "In situ study of chloride ingress in concretes containing natural zeolite, metakaolin and silica fume exposed to various exposure conditions in a harsh marine environment," Construction and Building Materials, vol. 46, pp. 63-70, 2013.

[14] F. A. Sabet, N. A. Libre, and M. Shekarchi, "Mechanical and durability properties of self consolidating high performance concrete incorporating natural zeolite, silica fume and fly ash," Construction and Building Materials, vol. 44, pp. 175-184, 2013.

[15] E. Vejmelková, D. Koňáková, T. Kulovaná et al., "Engineering properties of concrete containing natural zeolite as supplementary cementitious material: strength, toughness, durability, and hygrothermal performance," Cement and Concrete Composites, vol. 55, pp. 259-267, 2015.

[16] Y. Senhadji, G. Escadeillas, M. Mouli, and H. Khelafi, "Influence of natural pozzolan, silica fume and limestone fine on strength, acid resistance and microstructure of mortar," Powder Technology, vol. 254, pp. 314-323, 2014.

[17] A. Alhozaimy, G. Fares, O. A. Alawad, and A. Al-Negheimish, "Heat of hydration of concrete containing powdered scoria rock as a natural pozzolanic material," Construction and Building Materials, vol. 81, pp. 113-119, 2015.

[18] E. Ghafari, D. Feys, and K. Khayat, "Feasibility of using natural SCMs in concrete for infrastructure applications," Construction and Building Materials, vol. 127, pp. 724-732, 2016.

[19] M. Ghrici, S. Kenai, and M. Said-Mansour, "Mechanical properties and durability of mortar and concrete containing 
natural pozzolana and limestone blended cements," Cement and Concrete Composites, vol. 29, no. 7, pp. 542-549, 2007.

[20] N. Kaid, M. Cyr, S. Julien, and H. Khelafi, "Durability of concrete containing a natural pozzolan as defined by a performance-based approach," Construction and Building Materials, vol. 23, no. 12, pp. 3457-3467, 2009.

[21] C. Karakurt and I. B. Topçu, "Effect of blended cements produced with natural zeolite and industrial by-products on alkali-silica reaction and sulfate resistance of concrete," Construction and Building Materials, vol. 25, no. 4, pp. 1789-1795, 2011.

[22] H. Siad, "Influence of natural pozzolan on the behavior of self-compacting concrete under sulphuric and hydrochloric acid attacks, comparative study," 2010.

[23] M. I. Khan and A. M. Alhozaimy, "Properties of natural pozzolan and its potential utilization in environmental friendly concrete," Canadian Journal of Civil Engineering, vol. 38, no. 1, pp. 71-78, 2011.

[24] G. Fares, A. Alhozaimy, A. Al-Negheimish, and O. Abdalla Alawad, "Characterization of scoria rock from Arabian lava fields as natural pozzolan for use in concrete," European Journal of Environmental and Civil Engineering, vol. 89, pp. 1-19, 2019.

[25] V. Kočí, J. Kočí, M. Čáchová, E. Vejmelková, and R. Černý, "Multiparameter optimization of lime composite design using a modified downhill simplex method," Composites Part B: Engineering, vol. 93, pp. 184-189, 2016.

[26] K. Ellis, R. Silvestrini, B. Varela, N. Alharbi, and R. Hailstone, "Modeling setting time and compressive strength in sodium carbonate activated blast furnace slag mortars using statistical mixture design," Cement and Concrete Composites, vol. 74, pp. 1-6, 2016.

[27] Y. Shao, T. Lefort, S. Moras, and D. Rodriguez, "Studies on concrete containing ground waste glass," Cement and Concrete Research, vol. 30, no. 1, pp. 91-100, 2000.

[28] A. Khmiri, B. Samet, and M. Chaabouni, "A cross mixture design to optimise the formulation of a ground waste glass blended cement," Construction and Building Materials, vol. 28, no. 1, pp. 680-686, 2012.

[29] P. Chindaprasirt, W. Kroehong, N. Damrongwiriyanupap, W. Suriyo, and C. Jaturapitakkul, "Mechanical properties, chloride resistance and microstructure of Portland fly ash cement concrete containing high volume bagasse ash," Journal of Building Engineering, vol. 31, Article ID 101415, 2020.

[30] U. Mohd, G. Pandulu, and R. Jayaseelan, "Strength evaluation of eco-friendly concrete using Taguchi method," Materials Today: Proceedings, vol. 22, pp. 937-947, 2020.

[31] F. Zahiri and H. Eskandari-Naddaf, "Optimizing the compressive strength of concrete containing micro-silica, nano-silica, and polypropylene fibers using extreme vertices mixture design," Frontiers of Structural and Civil Engineering, vol. 13, no. 4, pp. 821-830, 2019.

[32] M. A. DeRousseau, J. R. Kasprzyk, and W. V. Srubar, "Computational design optimization of concrete mixtures: a review," Cement and Concrete Research, vol. 109, pp. 42-53, 2018.

[33] N. A. Soliman and A. Tagnit-Hamou, "Using particle packing and statistical approach to optimize eco-efficient ultra-high-performance concrete," ACI Materials Journal, vol. 114, no. 6, 2017.

[34] A. Alnuaim, Y. M. Abbas, and M. Iqbal Khan, "Sustainable application of processed TBM excavated rock material as green structural concrete aggregate," Construction and Building Materials, vol. 274, Article ID 121245, 2021.

[35] D. C. Montgomery, Design and Analysis of Experiments, Arizona State University, Tempe, AZ, USA, 8th edition, 2009.

[36] W. C. Rinaman, "Minitab," in Revival: The Handbook of Software for Engineers and.Sceince, pp. 1028-1046, CRC Press, Boca Raton, FL, USA, 2018.

[37] P. Perez-Cortes and J. I. Escalante-Garcia, "Alkali activated metakaolin with high limestone contents - statistical modeling of strength and environmental and cost analyses," Cement and Concrete Composites, vol. 106, Article ID 103450, 2020.

[38] M. J. Shannag, "High strength concrete containing natural pozzolan and silica fume," Cement and Concrete Composites, vol. 22, no. 6, pp. 399-406, 2000.

[39] M. J. Shannag and A. Yeginobali, "Properties of pastes, mortars and concretes containing natural pozzolan," Cement and Concrete Research, vol. 25, no. 3, pp. 647-657, 1995.

[40] M. S. Abdulrahman, A Study on Developing High Performance Non Shrinking Grout (HONG) Utilizing Local Materials, King Fahad University of Petroleum and Minerals, Dhahran, Saudi Arabia, 2015.

[41] B. Ali, H. Ahmed, L. Ali Qureshi et al., "Enhancing the hardened properties of recycled concrete (RC) through synergistic incorporation of fiber reinforcement and silica fume," Materials, vol. 13, no. 18, p. 4112, 2020.

[42] Y. M. Abbas, "Simplex-lattice strength and permeability optimization of concrete incorporating silica fume and natural pozzolan," Construction and Building Materials, vol. 168, pp. 199-208, 2018.

[43] H. Madani, M. N. Norouzifar, and J. Rostami, "The synergistic effect of pumice and silica fume on the durability and mechanical characteristics of eco-friendly concrete," Construction and Building Materials, vol. 174, pp. 356-368, 2018. 